\title{
ANALYSIS OF THE EVOLUTION OF THE CORONAVIRUS DISEASE RATE. CASE STUDY: ROMANIA, MARCH - NOVEMBER 2020
}

DOI: https://doi.org/10.18509/GBP210219r UDC: 303.71:[616.98:578.834(498)

\author{
Irina-Valentina Rădoi \\ Andrei Ducman \\ Camelia Teodorescu \\ Cristina-Valeria Popescu \\ Alexandra Grecu \\ Research Center for Integrated Analysis and Territorial Management (CAIMT), Faculty of \\ Geography, University of Bucharest, Queen Elizabeth Blvd 4, Bucharest 030167, Romania
}

\begin{abstract}
The Coronavirus pandemic has been a challenge for the entire population of the Earth, andthe national administration of the states has experienced difficult times in trying to limit the spread of the new virus. The effects of the pandemic were strongly felt at the economic level, displacing a large part of the population from their jobs, but also at the demographic level, with massive returns to the country of romanians working abroad. The primary objective of the study was to analyze the evolution of the disease rate, calculated by reporting the number of positive tests to the number of tests performed that day. The secondary objective of the study was to highlight the fact that a higher testing capacity will lead to an increase in the number of cases at the state level. The aim of the study was to raise awareness of the need to address responsible behavior in the face of such a challenge. The results of the study identified that in order to understand the real situation it is necessary to analyze the above mentioned rate, as the number of positive tests shows a tendency of direct proportionality with the number of tests performed per day.
\end{abstract}

Keywords: virus, medical geography, COVID-19, health, medicine

\section{INTRODUCTION}

The impact of new viruses on medicine is intense and unpredictable, giving the need to stay alert to potentially devastating global or local pandemics, and the SARS-CoV-2 pandemic has caused incredible changes in a multitude of economic sectors. in the mentality and behavior of societies, as well as the dynamization of the relationship between the national administration and the population, causing a series of mistrusts, fears and effects that have contributed decisively to the transformation of current inter-human relations [1][8][7]. Emergency prevention measures have been a problem for the national administration of the states that have become recipient poles of the virus, thus illustrating a number of important elements of existing societies [2][5][6]. The prevention method and the degree of acceptance of the measures are stimulated by a series of extremely variable factors and with very fast fluctuations, the fake-news phenomenon contributing decisively in impatient some vulnerable socio-human categories, hindering the national administration's mission to properly manage the delicate situation., such as the current Coronavirus pandemic.[3][6][9]. The Romanian state entered the list of recipient states of the virus in February 2020, and will see a significant increase in the number of cases 
since then, representing the starting point in a large decision-making process to maintain control of the virus, by establishing emergencies., alert states, lockdown measures, the closure of schools, but also the hotel and restaurant industry, decimating the economy on many distinct levels, registering drastic economic declines and closing many small and medium businesses that could not self-sufficient. financially support during the pandemic. The evolution of the virus was very fast, unpredictable, sudden and extremely dynamic, developing new symptoms, new forms of transmission, but also an important resistance against existing prevention measures [4][10]. Campaigns to promote prevention measures were carried out in Romania on all existing social and media channels, through public and private television, through local and national newspapers, but also through people with a significant media influence, injecting considerable sums in promoting aggressive awareness of these SARS-CoV-2 efficacy campaigns and its dangers. The research contributes to the development of the specialized literature for the medical field, but also for the development of an overview on the SARS-CoV-2 pandemic on the Romanian territory.

\section{METHODOLOGY}

The research was carried out through daily data, provided by the Romanian Government, public data that were later transformed into graphics using the Microsoft Office bundle, especially Microsoft Excel. To perform the study, the daily infection rate was calculated, obtained by finding the weights of the positive tests from the total daily tests, thus illustrating the degree of efficiency of the virus. The study proposes the analysis of the period March 1 - November 30, 2020, perfectly illustrating the most important periods of evolution of the SARS-CoV-2 pandemic in Romania, starting from the first cases, as well as the way in which the most important measures had an impact on the evolution of the infection rate. The analysis of the infection rate produces an increase of the authenticity and importance of the study, in view of the fact that the number of daily tests is variable, by operating in public-private partnership during the week, following the weekends to be made only by testing in private partner centers. producing a considerable decrease in the number of tests.

\section{RESULTS}

March 2020 represented the beginning of the first cases in Romania, the testing period of potential new cases, but also of the first emergency measures in the state. The general growth trend is an upward one, producing an increase in the infection rate of over $18.8 \%$ for this month. The establishment of the state of emergency, by the President of Romania, on March 16, 2020, did not produce an immediate decrease in the number of cases, this decrease being observed in April (Figure 1).

April 2020 obtained a decrease in the infection rate by over $7.8 \%$ over the analyzed period, the general trend being a downward one, due to the quarantine measures decided in the previous month. Due to the impossibility of leaving the home without urgent reasons, the transmission possibilities decreased considerably, the new cases being rather correlated with the previous cases, managing to keep an optimal control to understand the transmission mode and transmission frequency of the virus. Easter did not represent a dynamic factor of the infection rate, due to the impossibility of leaving the existing quarantine measures at national level (Figure 2). 


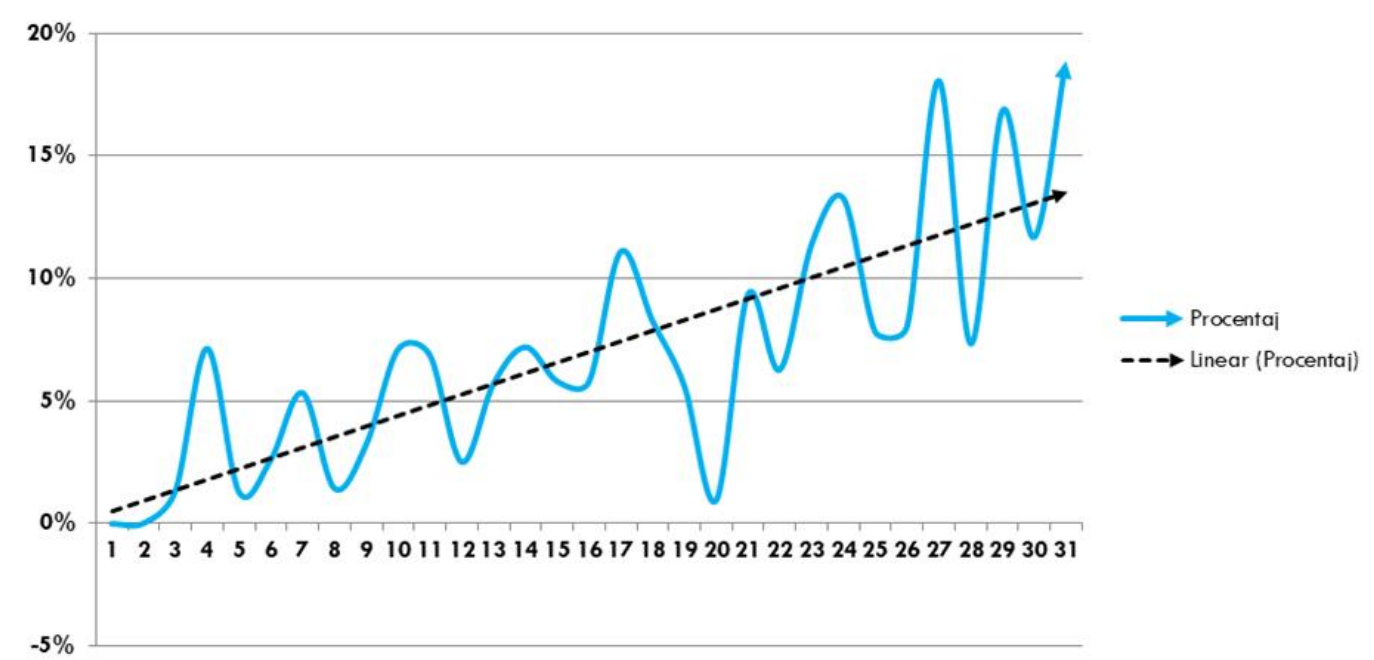

Figure 1. Evolution of the SARS-CoV-2 virus infection rate, March 2020

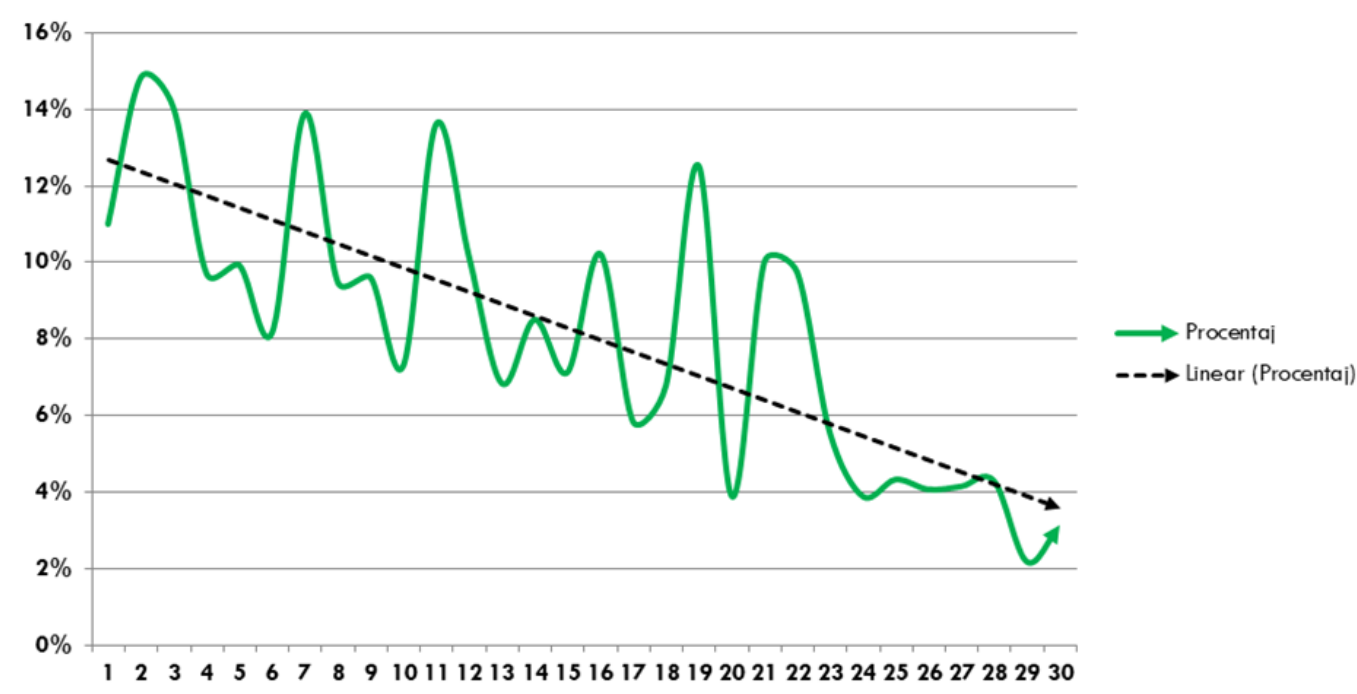

Figure 2. Evolution of the SARS-CoV-2 virus infection rate, April 2020

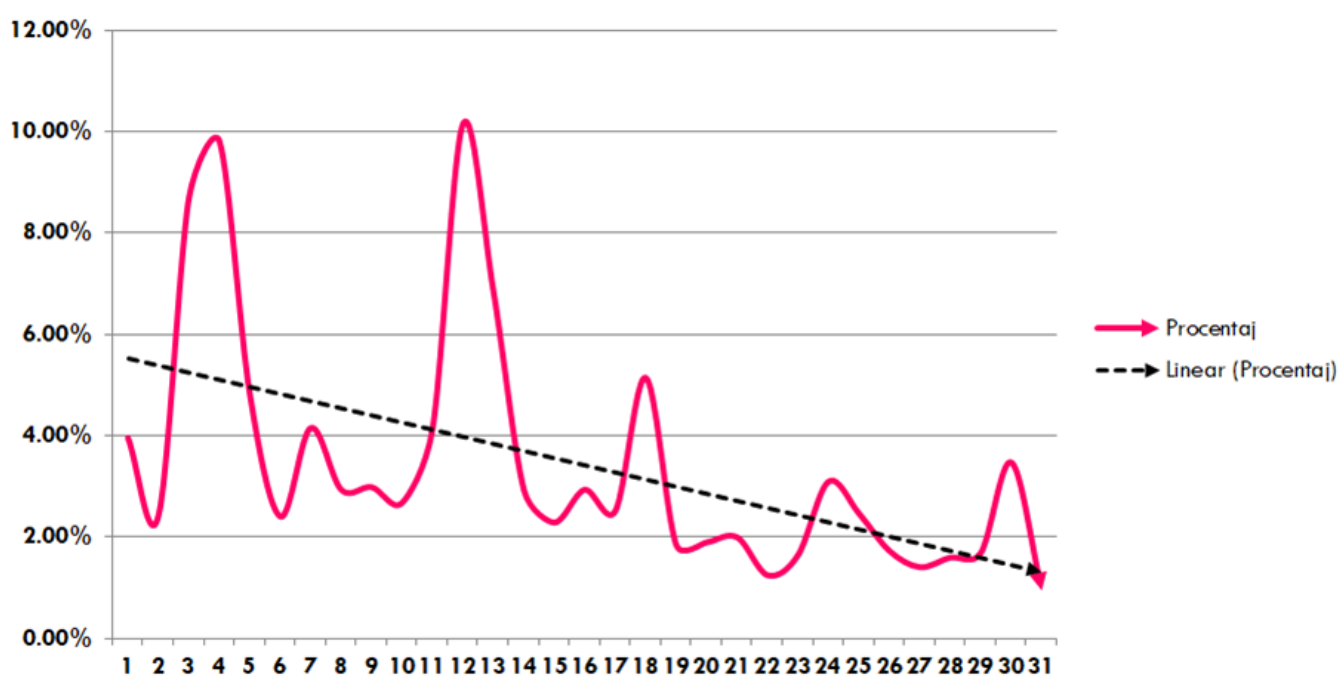

Figure 3. Evolution of the SARS-CoV-2 virus infection rate, May 2020 
May 2020 represented the end point for the state of emergency, establishing a state of alert on May 15, wishing a relaxation of emergency measures, due to the decreases recorded in the previous month. Relaxation measures were not a positive element in combating the SARS-CoV-2 virus, but the pressure of the population on the national administration became more and more oppressive, so that these measures were necessary to release the economy and social mentality, although the pandemic management increased to a certain extent much more difficult to control. The general trend is one of decrease, the consequences of the relaxation measures being observable for June 2020 (Figure 3).

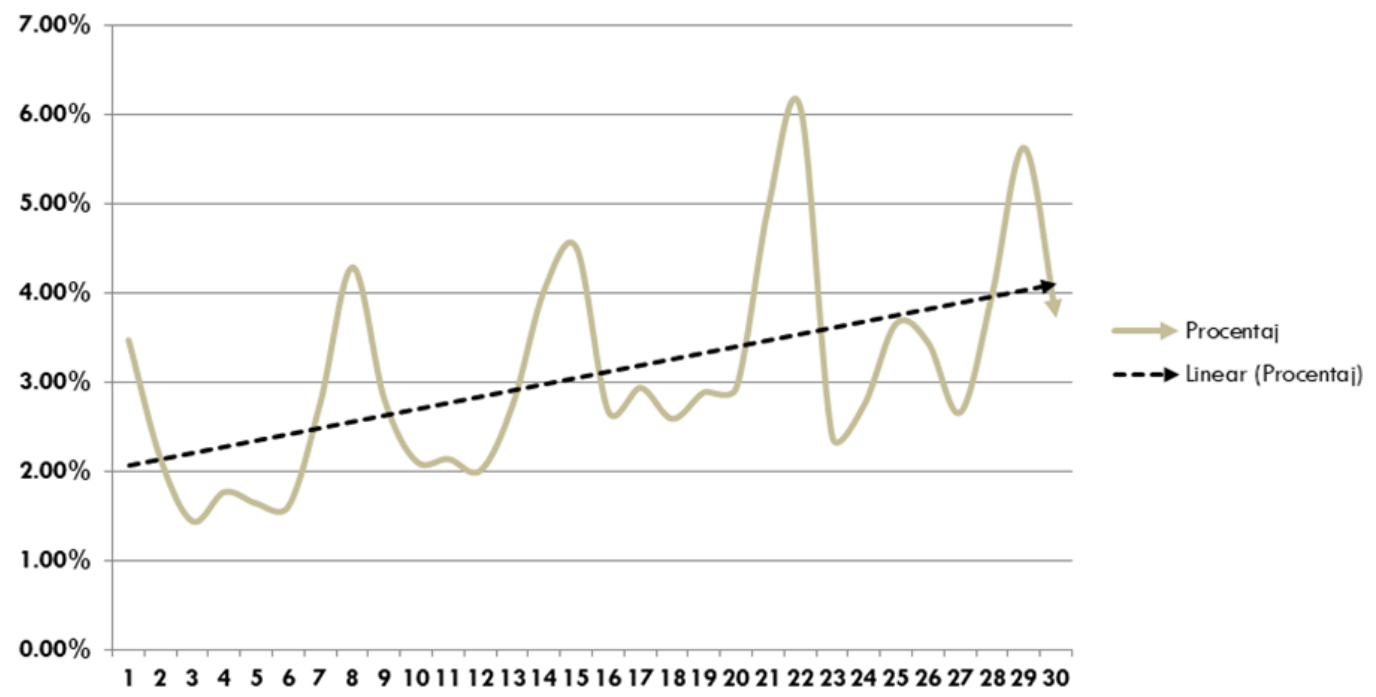

Figure 4. Evolution of the infection rate with SARS-CoV-2 virus, June 2020

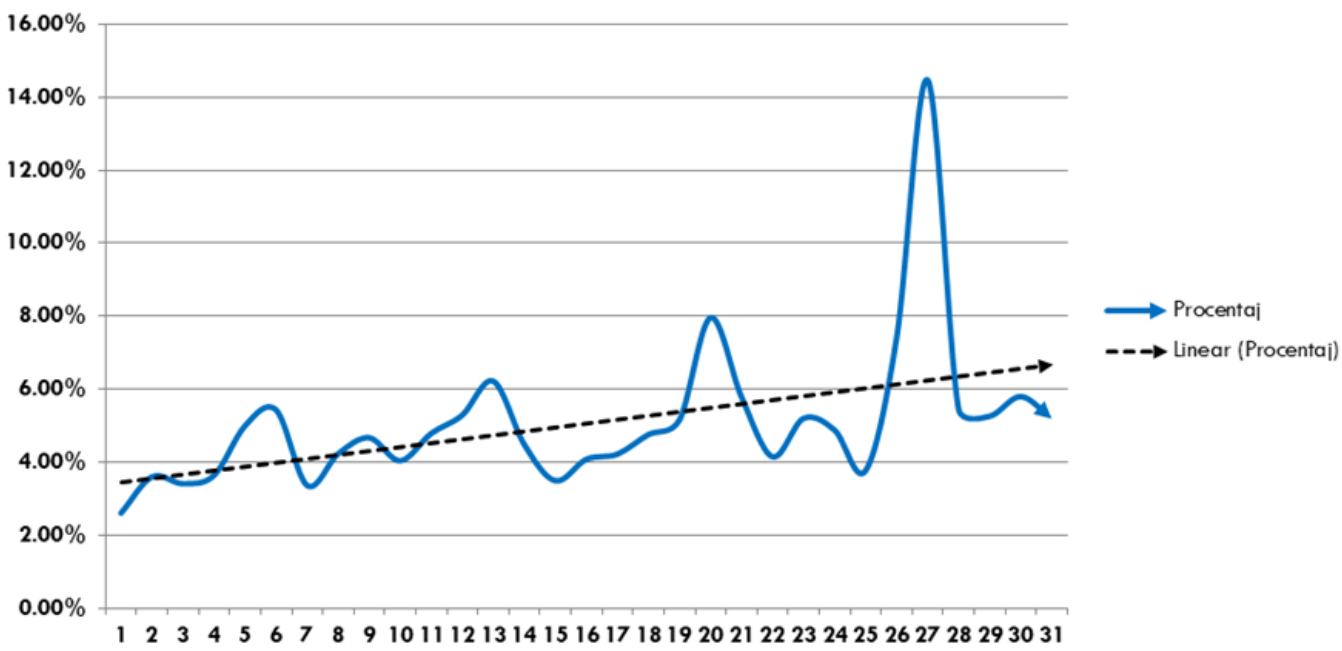

Figure 5. Evolution of the SARS-CoV-2 virus infection rate, July 2020

The relaxation measures proposed by the national administration have increased the efficiency of the virus and the transmission rate, but within controllable limits, the maximum period being at the percentage of approximately $6 \%$. Also, the gradual opening of the summer season and of the hotel industry produced an increase of coronavirus cases, their epicenter being mostly the Romanian coast, but also the mountainous area of Romania. The continuation of the alert state was necessary to guarantee a minimum 
control necessary for the national administration. The general trend is an ascending one, but the liberalization of the measures produced the decongestion of the relationship between the national administration and the population, but also the relaunch of some economic sectors affected by the pandemic. (Figure 4)

With the opening of the summer season and the liberalization of emergency measures, the population's confidence in tourist trips increased considerably, which continued the gradual increase in the number of coronavirus cases, reaching a maximum of $14.4 \%$ in July (Figure 5).

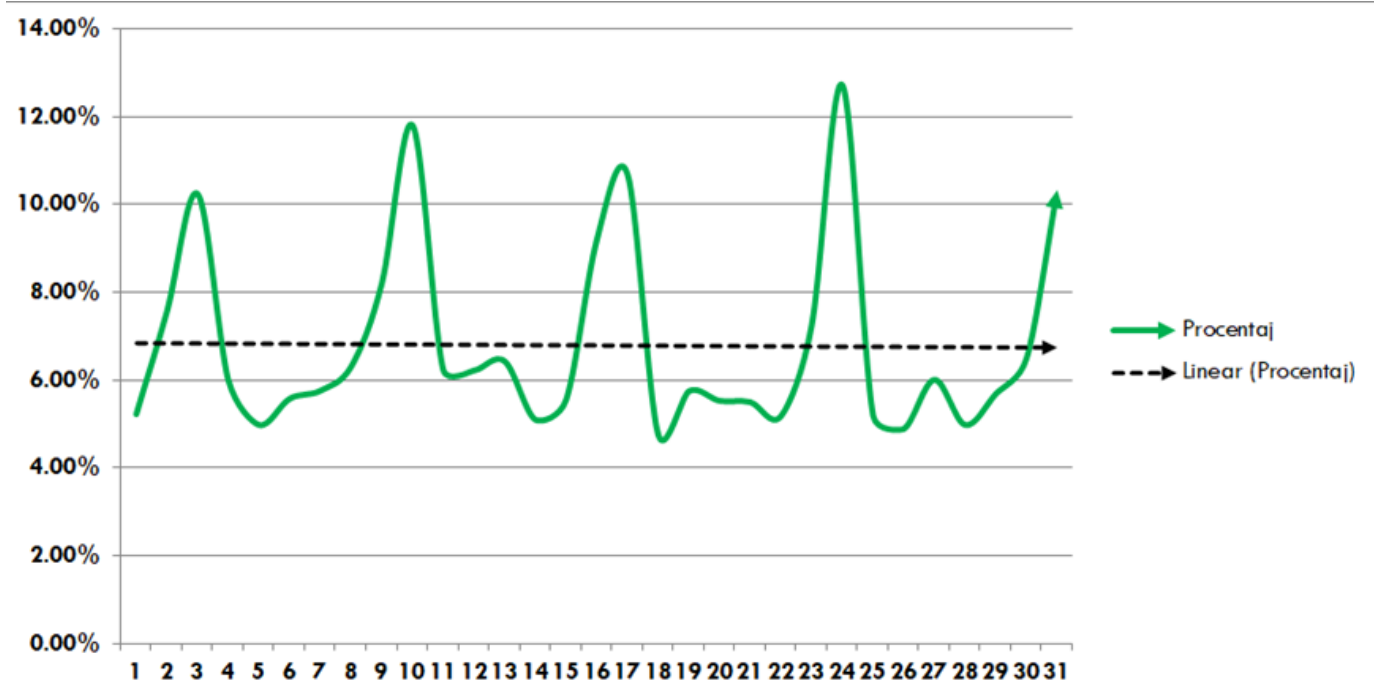

Figure 6. Evolution of the SARS-CoV-2 virus infection rate, August 2020

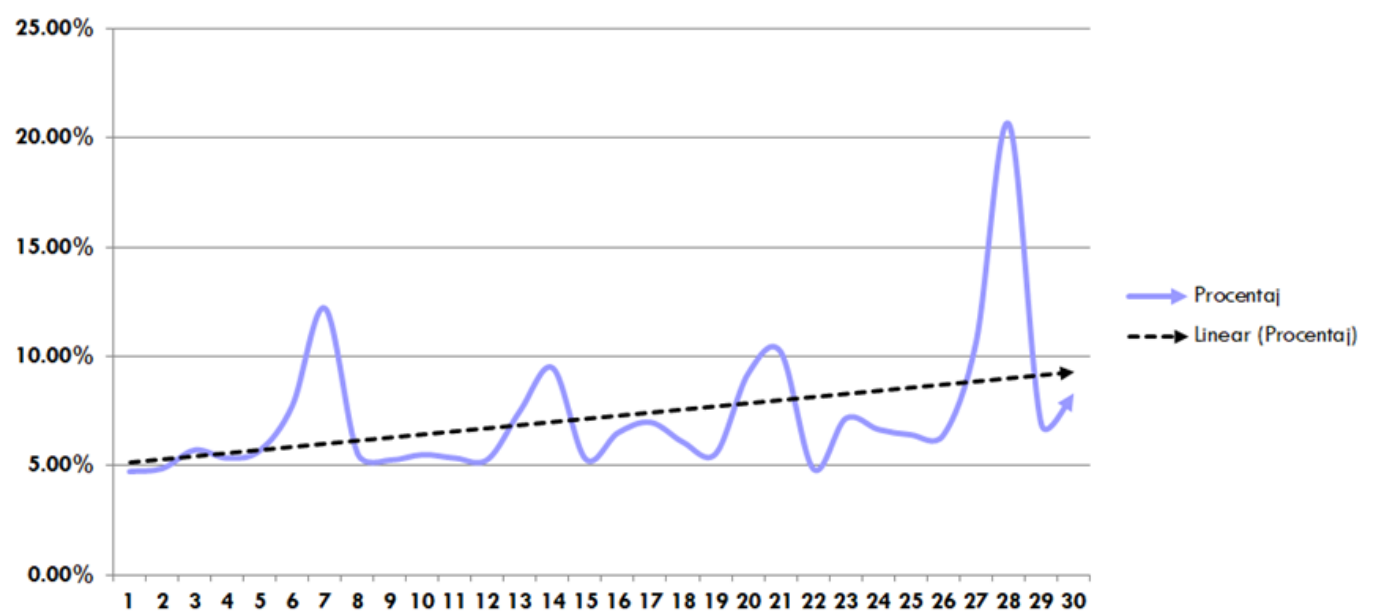

Figure 7. Evolution of the SARS-CoV-2 virus infection rate, September 2020

The continuation of tourist activities led to an increase in the minimum infection rate from $2.6 \%$ to $4.75 \%$ between July and August, thus continuing the considerable increase in the number of cases nationwide, generated by domestic and international tourist trips. Although the trend is one of stagnation, the fluctuating evolution of the number of cases indicates that there is no exact stability of the test centers, being very unlikely extremely sudden decreases in the rate in just a few days. The maximum recorded in August is $12.71 \%$, but it is important to mention that there are at least five periods of infection rate over $10 \%$ (Figure 6). 
September led to a further increase in the minimum infection rate, exceeding the 5\% threshold, but it is important to note that the daily infection rate reached a record high of over $20 \%$, along with an upward trend. The unpredictability of the pandemic in the country was increasing considerably, the control of cases being extremely difficult to manage, the hospitalization and testing centers being supersaturated during this period. September also began with the opening of schools, which facilitated the growth observed in October (Figure 7).

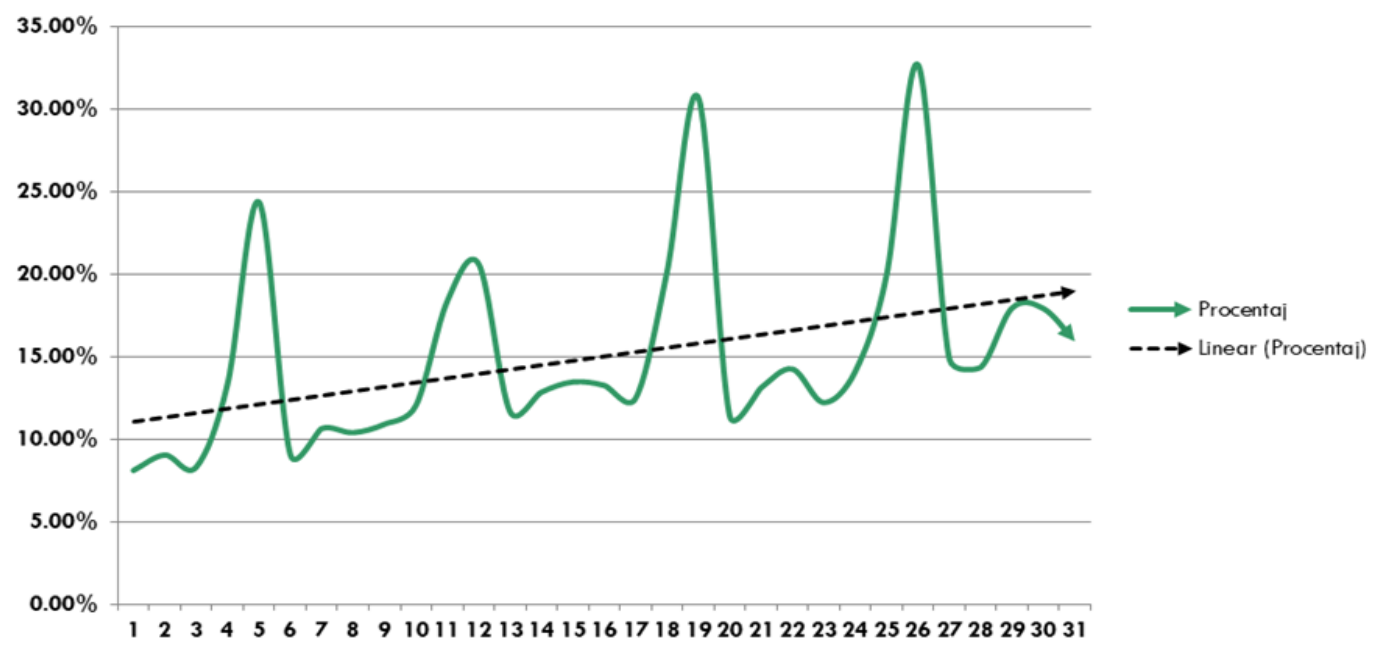

Figure 8. Evolution of the SARS-CoV-2 virus infection rate, October 2020

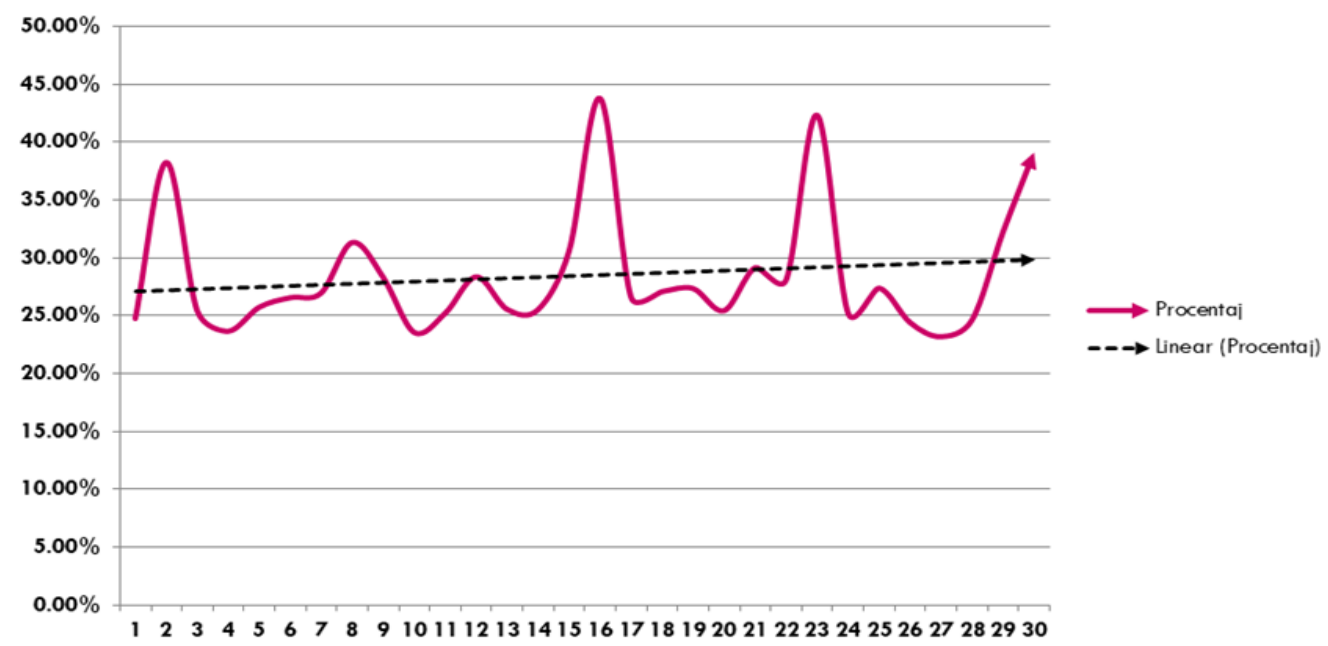

Figure 9. Evolution of the SARS-CoV-2 virus infection rate, November 2020

The increase in aces and the minimum infection rate are correlated with the opening of schools, thus increasing the possibility of transmitting the SARS-CoV-2 virus to all sociohuman categories, the minimum graph being recorded at $8 \%$, reaching a new historical maximum, of over $32.6 \%$. It is important to highlight the fact that the existing alert state did not present efficiency in the face of challenges and decision pressures on the situation of schools and the efficiency of online education, registering multiple values above the threshold of $20 \%$ (Figure 8).

The closure of schools becomes inevitable in the process of preventing and stopping the SARS-CoV-2 virus, despite fluctuating social pressures, so the Romanian Government 
decides to close schools and restaurants, but also to establish measures to prevent the virus by banning them from leaving their homes. in the time interval $23-05$, without presenting a statement on his own responsibility and a good reason. The measure wanted to stop private party events, but the minimum schedule already reached the value of $23 \%$, making it difficult to develop prevention and stopping measures, reaching a maximum of $43.7 \%$, despite a stagnant trend (Figure 9).

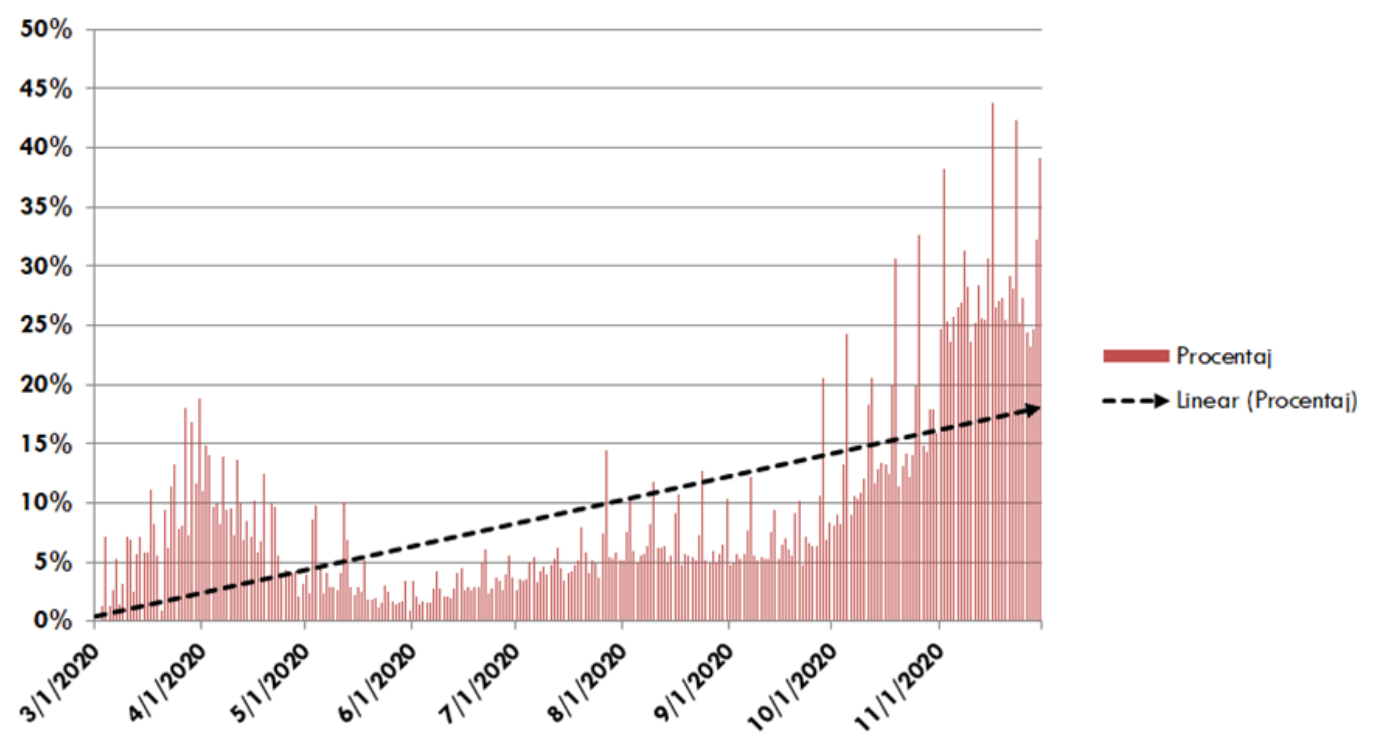

Figure 10. Evolution of the SARS-CoV-2 virus infection rate, March - November 2020

The infection rate experienced an overall period of upward evolution, through a considerable increase in the infection rate for the analyzed period, distinguishing an increase of over $43 \%$ for the analyzed interval. Reaching the first peak was achieved in April, continued by its completion, followed by a period of slight growth for the summer. The beginning of autumn and the considerable relaxation of the measures led to the increase of the infection rate to a new peak for the period October - November 2020 (Figure 10).

\section{CONCLUSIONS}

Due to its unpredictability, the possibility of self-destruction of the economy through poorly managed measures, but also through possible emergency measures that may distort the relationship in the population's trust in local government, the Coronavirus pandemic was a challenge for the Romanian authorities, but also for citizens and entrepreneurs. The study confirms the initial premises, according to which the total number of tests contributes decisively to the increase of the number of positive tests, and the calculation of the infection rate is most effective, by its reduced possibility to provide erroneous data or that could be misunderstood. The research also shows that the statistics provided by the national administration can be misunderstood, through a reduced testing capacity for weekends, thus providing potential misunderstandings among citizens, thus fueling the pressure of the national community on leadership. state. Also, the study reveals that Romania has exceeded the first peak of the pandemic, carried out between March and May, followed by a second peak, starting in the fall of 2020, carried out until the final period of the study. 


\section{REFERENCES}

[1] de Andrade, F.M.D. et. al, 2021. Twitter in Brazil: Discourses on China in times of coronavirus. Social Sciences \& Humanities Open, Vol. 3, Issue 1, available online at: https://doi.org/10.1016/j.ssaho.2021.100118.

[2] Delis, D.M. et. al, 2021. The impact of the coronavirus crisis on the market price of risk. Journal of Financial Stability, Vol. 53, available online at: https://doi.org/10.1016/j.jfs.2020.100840.

[3] Gombar, S. et. al, 2021. SARS-CoV-2 infection and COVID-19 severity in individuals with prior seasonal coronavirus infection. Diagnostic Microbiology and Infectious Disease, available online at: https://doi.org/10.1016/j.diagmicrobio.2021.115338.

[4] Pintilii R.D. et. al, 2017. Socio-Economic Geography Creative economies in Romania-spatial projections and trends, Bulletin of Geography, Socio-economic Series, Vol. 37, pp 95-108.

[5] Rădoi I.V. et. al, 2020. The impact of the development of the local economy on the natural environment of the Danube Delta, Romania, Public recreation and landscape protection, pp. 489.

[6] Rossi, G. et. al, 2021. Therapeutic approaches to coronavirus infection according to "One Health" concept. Research in Veterinary Science, available online at: https://doi.org/10.1016/j.rvsc.2021.02.009.

[7] Segars, M.D.J. et. al, 2020. Prior and novel coronaviruses, Coronavirus Disease 2019 (COVID-19), and human reproduction: what is known?. Fertility and Sterility, Vol. 113, Issue 6, pp. 1140-1149.

[8] Teodoresc, C., \& Szemkovics, L.S., 2017. The ethno-creativity in the pilot centers in Romania and their role in the development of cultural tourism and the educational process, Geographical studies and environment protection research vol. 16, nr. 1, pp. 88-97, 2017

[9] Teodorescu C. et. al, 2019. Disfunctionalities in the Organization and Development of SPA Tourism Developed on Salt Resources in Maramureș, Romania, Public Recreation and Landscape Protection, Vol. 1, pp 101-105.

[10] Teodorescu C. et. al, 2016, Religious and cultural tourism and the socio-economic and educational implications. Quaestus Multidisciplinary Research Journal, Vol. 8, pp 227- 285.

[11] Teodorescu C. 2009. Turism cultural, Editura Transversal, Targoviste, Romania. 